\title{
Preoperative C-reactive protein/albumin ratio is a significant predictor of survival in bladder cancer patients after radical cystectomy: a retrospective study
}

This article was published in the following Dove Press journal: Cancer Management and Research

\author{
Yadong Guo 1,* \\ Keke Cai ${ }^{2, *}$ \\ Shiyu Mao',* \\ Junfeng Zhang' \\ Longsheng Wang' \\ Ziwei Zhang' \\ Mengnan Liu ${ }^{3}$ \\ Wentao Zhang ${ }^{3}$ \\ Yuan Wu ${ }^{3}$ \\ Yang Yan' \\ Xudong Yao' \\ 'Department of Urology, Shanghai \\ Tenth People's Hospital, Tongji \\ University, Shanghai, People's Republic \\ of China; ${ }^{2}$ Department of Urology, \\ First Affiliated Hospital of Anhui \\ Medical University, Hefei, People's \\ Republic of China; ${ }^{3}$ Department of \\ Anhui Medical University, Hefei, \\ People's Republic of China \\ *These authors contributed equally to \\ this work
}

Correspondence: Yang Yan Department of Urology, Shanghai Tenth People's Hospital, Tongji University, 30I Yanzhong Road, Jing'an District, Shanghai 200040, People's Republic of China

Tel +86 216630 I073

Email 13564368328@।63.com

Xudong Yao

Department of Urology, Shanghai Tenth People's Hospital, Tongji University, 30I Yanzhong Road, Jing'an District, Shanghai 200040, People's Republic of China Email yaoxudong1967@I63.com
Purpose: Earlier studies have indicated the prognostic value of the pretreatment C-reactive protein (CRP)/albumin ratio (CAR) in multiple tumor types. The present study attempts to investigate the predictive role of preoperative CAR in patients with bladder cancer after radical cystectomy (RC), and explores its prognostic index value.

Patients and methods: A total of 131 patients with bladder cancer after RC between 2009 and 2015 were analyzed in the present study. Overall survival (OS) and progression-free survival (PFS) were estimated using the Kaplan-Meier method and Cox regression analyses. Prediction accuracy was evaluated through the area under the receiver operating characteristic curve (AUC). Results: The median follow-up time for all patients in the present retrospective study was 39.72 months (15.51-53.26 months). The Kaplan-Meier curve analysis indicated that bladder cancer patients with high preoperative CAR $(>0.2)$ were significantly associated with decreased PFS and OS (all, $P<0.001$ ). The multivariate analysis confirmed CAR as a common independent prognostic factor for PFS and OS. Furthermore, the effective combination of CAR and pathological T staging constituted a new index (CART), and was observed to be an independent risk factor for OS (CART score $=2, \mathrm{HR}=0.264 ; 95 \% \mathrm{CI}$ : 0.106-0.660, $P=0.004$; CART score $=3$, $\mathrm{HR}=0.371 ; 95 \% \mathrm{CI}: 0.208-0.661, P=0.001)$. However, CART did not show any prognostic significance for PFS. Importantly, the AUC values of CAR for OS and PFS were higher than other conventional clinical indices.

Conclusion: The present study demonstrated that CAR can be used as a new prognostic indicator of OS and PFS in patients with bladder cancer after RC. Combining the CAR score with pathological $\mathrm{T}$ staging as the CART score appears to be a more effective prognostic indicator of poor OS, but not PFS.

Keywords: bladder cancer, radical cystectomy, prognostic model, C-reactive protein/albumin ratio (CAR)

\section{Introduction}

Bladder cancer is the most common malignancy of the urinary system in the US, with an estimate of 81,190 new diagnoses and 17,240 deaths expected in the present year. ${ }^{1}$ The standard treatment options for muscular invasive bladder cancer (MIBC) and high risk non-muscle invasive bladder cancer (NMIBC) are radical cystectomy (RC) and pelvic lymph node dissection. ${ }^{2}$ The overall 5-year relative survival rate has been $77 \%$ for all stages of bladder cancer, while this rate was $96 \%$ for in situ urinary bladder cancer, $81 \%$ for patients with non-muscle-invasive disease, and $47 \%$ for patients with 
muscle-invasive disease. ${ }^{3}$ In addition, the outcome of bladder cancer after $\mathrm{RC}$ has been heterogeneous, and its prognosis is relatively poor, especially in high-grade and metastatic bladder cancer. In recent years, additional aggressive methods have been attempted to improve clinical outcomes, such as the use of neoadjuvant chemotherapy in MIBC patients, and early RC in high-risk NMIBC patients. ${ }^{4,5}$ However, these additional treatments run the risk of overtreatment, especially in patients with a good prognosis. Thus, it is very important to find biomarkers that can help clinicians to screen suitable patients for proper treatment and develop effective followup strategies.

In recent years, focus has been given in studying the role of immunity and nutrition in tumor prognosis. ${ }^{6,7} \mathrm{An}$ increasing body of evidence has indicated that inflammation plays an important role in carcinogenesis and tumor progression. For example, inflammation was observed to regulate biological behavior at different stages of tumor development. ${ }^{8}$ In addition, inflammatory cells and immune response have been considered to be correlated with tumor prognosis. ${ }^{9} 10$ Some studies have revealed that peripheral blood cells, including neutrophils, lymphocytes and platelets, may promote tumor cell proliferation, migration and invasion, ${ }^{11,12}$ and C-reactive protein (CRP), which is directly correlated to the circulating concentration of vascular endothelial growth factor (VEGF), promotes the development of cancer. ${ }^{13}$ The albumin protein level assessment in the body can reflect the nutritional status of cancer patients, and malnutrition has been commonly observed in solid tumors, especially during cancer progression. ${ }^{14}$ Furthermore, it is evident that malnutrition can weaken human immune response and phagocytic function, thereby impacting cancer patient survival. ${ }^{15}$ Recent studies have highlighted the important predictive effects of some inflammatory and nutritional-related indicators such as the prognostic nutritional index (PNI), platelet-to-lymphocyte ratio (PLR) and neutrophil-to-lymphocyte ratio (NLR), on bladder cancer prognosis. ${ }^{16-18}$ However, based on the correlation of inflammation and nutrition to prognosis, a new prognostic index, $\mathrm{CRP} /$ albumin ratio (CAR), has emerged to be an independent indicator of poor prognosis in different malignancies, including liver, lung, pancreatic, esophageal and cervical malignancies. ${ }^{19-23}$ However, its potential prognostic role has not been evaluated in patients with bladder cancer. Therefore, in the present study, the investigators attempted to determine the prognostic role of CAR in bladder cancer and develop a new prognostic model, especially in patients with bladder cancer, who underwent RC.

\section{Materials and methods}

\section{Patient selection}

A total of 131 patients with bladder cancer, who underwent RC at the Urology Department of Shanghai Tenth People's Hospital between 2009 and 2015, were recruited in the present study. A written informed consent was obtained from each patient prior to enrollment into the study. This study was approved by the Medical Ethics Committee of Shanghai Tenth People's Hospital. Information on their clinical and pathological features, including age, body mass index (BMI), gender, history of diabetes mellitus, hypertension, heart and cerebrovascular disease, smoking history, histology type, American Society of Anesthesiologists (ASA) grade, pathological lymph-node status, pathological T stage and differential grade, was collected. Histological subtype was diagnosed by at least two experienced pathologists on the basis of the 1973 WHO criteria, while TNM staging was assessed using the American Joint Committee on Cancer staging system (seventh edition, 2010). Blood samples were collected within 2 days prior to surgery. Patients with acute or chronic infection, who received chemotherapy or radiotherapy before surgery, who had hematological and autoimmune disorders, or who did not have available follow-up data, were excluded. Moreover, patients whose clinical information could not be completely obtained were also excluded from the present analysis.

\section{Follow-up and evaluation}

Patient follow-up after RC was performed every 3 months for the first 2 years and every 6 months for another 3 years. Then, the follow-up was performed yearly thereafter. Postoperative investigations primarily included physical examination and imaging, in order to assess hydronephrosis and cancer recurrence. The last survival follow-up date was March 31, 2018. The study endpoints were PFS and OS, where PFS was defined as the time from the date of surgery to the time of disease recurrence, metastasis, or death, while OS was defined as the time from the day of surgery to the time of death due to any cause. CAR was calculated as the $\mathrm{CRP} /$ albumin ratio, PNI was calculated as albumin level $(\mathrm{g} / \mathrm{L})+5 \times$ lymphocyte count $\left(10^{9} / \mathrm{L}\right)$, PLR was calculated as platelet count/lymphocyte count, and NLR was calculated by dividing the neutrophil count with the lymphocyte count.

\section{Statistical analysis}

X-tile software v3.6.1 (Yale University, New Haven, CT, USA) was used to determine the optimal cutoff values for NLR, PLR, PNI, and CAR. ${ }^{24}$ SPSS v24.0 (IBM Corpora- 
tion, Armonk, NY, USA) software was used for all statistical analyses. Frequencies and proportions are reported for categorical variables. The chi-squared test was used to evaluate the association between clinicopathological data and CAR. The correlations with PFS and OS were assessed using Kaplan-Meier curves with log-rank statistics. Furthermore, factors that were deemed significant by univariate analysis were included in the Cox proportional-hazards multivariate model to estimate the hazard ratios (HRs) and 95\% confidence intervals (CIs). Receiver operating characteristics (ROC) curves, which define the sensitivity, specificity, and differences in the area under the curve (AUC) were detected using MedCalc version 15.2.0 Software. A $P$-value $<0.05$ was considered statistically significant.

\section{Results \\ Patient characteristics}

The 131 patients included in the present study had a median age of 66 years old (range 58-75 years old). Among these patients, $62(47.3 \%)$ patients were current or former smokers. Furthermore, MIBC was diagnosed in 77 patients (58.8\%), while lymph nodal metastasis was observed in 15 patients (11.5\%). During the median follow-up of 39.72 months (15.51-53.26 months), 65 patients had disease progression (49.6\%), while 61 patients died (46.6\%). The detailed characteristics of the complete cohort are described in Table 1.

\section{The association between clinicopathological features and CAR}

The X-tile software determined the following cutoff values: CAR, 0.2; PNI, 38.5; PLR, 210.9; NLR, 3.8 (Figure 1 and Figure S1). Based on these cutoff values, the 131 patients were divided into two groups: low-CAR group $(n=83$, $63.4 \%)$, and high-CAR group $(n=48,36.6 \%)$. Compared with the low-CAR group, the high-CAR (>0.2) group was found to be significantly associated with older age, high BMI, T-stage, N-stage, lower PNI, and high NLR and PLR (Table 1).

\section{Analysis of the prognostic value of CAR}

The Kaplan-Meier analysis revealed the association of high CAR value with shorter PFS and OS (all, $P<0.001$, Figure 2). In addition, patients in the high-CAR group had lower cumulative 5-year PFS rates, when compared to patients in the low-CAR group (30.2\% vs $56.0 \%$, respectively; $P<0.001)$. A similar trend was observed for OS rates (14.6\% vs $68.0 \%$, respectively; $P<0.001)$. In addition, the univariate analysis highlighted smoking history $(P<0.001)$, T staging $(P<0.001)$,
$\mathrm{N}$ staging $(P=0.028)$, ASA grade $(P=0.033), \mathrm{PNI}(P=0.006)$ and CAR $(P<0.001)$ as factors significantly correlated to PFS (Table 2$)$. In contrast, age $(P=0.01)$, smoking history $(P<0.001), \mathrm{T}$ staging $(P<0.001), \mathrm{N}$ staging $(P=0.018), \mathrm{M}$ staging $(P=0.018)$, ASA grade $(P=0.013)$, NLR $(P<0.001)$, $\operatorname{PLR}(P=0.01)$, PNI $(P=0.002)$ and CAR $(P<0.001)$ were significantly associated with OS (Table 3 ). However, the multivariate Cox regression model only confirmed smoking history (HR: 4.128; 95\% CI: 2.332-7.305; $P<0.001)$, T staging (HR: 2.445; 95\% CI: $1.345-4.443 ; P=0.003$ ), ASA grade (HR: 2.128; 95\% CI: 1.025-4.416; $P=0.043$ ) and high CAR (HR: 1.893; 95\% CI: $1.150-3.144 ; P<0.012$ ) as independent risk factors for PFS (Table 2). In addition, smoking history (HR: 4.169; 95\% CI: 2.218-7.835; $P<0.001)$, T staging (HR: 3.361; 95\% CI: 1.601-7.055; $P<0.001), \mathrm{M}$ staging (HR: 4.006; 95\% CI: 1.494-10.742; $P=0.006)$, high CAR (HR: 3.063; 95\% CI: 1.788-5.249; $P<0.001$ ) were the only confirmed independent factors that have a significant association with OS (Table 3). Overall, the present analysis strongly demonstrates that preoperative CAR is an independent predictor for PFS and OS in patients with bladder cancer after RC.

\section{Analysis of the prognostic value of the new index CART}

Based on the multivariate analysis and prognostic models, it was observed that along with CAR scores, pathological $\mathrm{T}(\mathrm{pT})$ staging was also a significant predictor for patients with bladder cancer. Therefore, $\mathrm{pT}$ staging was combined with the CAR score, and a new CART score was created. The CART score categorization was performed, as follows: $\mathrm{CART}=1(\mathrm{CAR} \leq 0.2$ and $\mathrm{pT}$ staging $=\mathrm{MIBC})$; CART $=2$ $(\mathrm{CAR} \leq 0.2$ and $\mathrm{pT}$ staging $=\mathrm{MIBC}$ or $\mathrm{CAR}>0.2$ and $\mathrm{pT}$ staging $=$ NMIBC $)$, and CART $=3(\mathrm{CAR}>0.2$ and $\mathrm{pT}$ staging $=$ NMIBC). This shows that a lower CART score is associated with a higher risk of bladder cancer. Based on this criterion, the CART score was analyzed based on the univariate and multivariate analysis. The Kaplan-Meier analysis indicated that the CART score is a significant indicator of poor OS in all patients $(P<0.001$, Figure 3$)$. The multivariate analysis revealed that a high CART score was an independent risk factor for OS in bladder cancer patients (CART score $=2$, HR $=0.264 ; 95 \%$ CI: $0.106-0.660, P=0.004$; CART score $=3$, HR $=0.371$; $95 \%$ CI: $0.208-0.661, P=0.001$; Table 4 ). However, these CART scores appeared to lose their predictive value for PFS (Table 5). Overall, these present results imply that the CART score is a superior prognostic factor for OS, when compared to CAR. 
Table I The correlation between preoperative CAR and clinicopathological characteristics

\begin{tabular}{|c|c|c|c|c|}
\hline Variable & Cases $(n=|3|)$ & $\begin{array}{l}\text { CAR } \leq 0.2 \\
(n=83)\end{array}$ & CAR >0.2 $(n=48)$ & $P$-value \\
\hline Age & & & & 0.001 \\
\hline$\leq 65$ years & $65(49.6)$ & $50(60.2)$ & I5 (3I.3) & \\
\hline$>65$ years & $66(50.4)$ & $33(39.8)$ & $33(68.8)$ & \\
\hline BMI & & & & 0.033 \\
\hline$<24$ & $77(58.8)$ & $43(51.8)$ & $34(70.8)$ & \\
\hline$\geq 24$ & $54(4 \mid .2)$ & $40(48.2)$ & $14(29.2)$ & \\
\hline Gender & & & & 0.754 \\
\hline Male & II $3(86.3)$ & $71(85.5)$ & $42(87.5)$ & \\
\hline Female & $18(13.7)$ & $12(14.5)$ & $6(12.5)$ & \\
\hline Smoking history & & & & 0.055 \\
\hline No & $69(52.7)$ & $49(59.0)$ & $20(4 \mid .7)$ & \\
\hline Yes & $62(47.3)$ & $34(31.0)$ & $28(58.3)$ & \\
\hline Hypertension & & & & 0.071 \\
\hline No & $99(75.6)$ & $67(80.7)$ & $32(66.7)$ & \\
\hline Yes & $32(24.4)$ & $16(19.3)$ & $16(33.3)$ & \\
\hline Diabetes mellitus & & & & 0.22 \\
\hline No & $108(82.4)$ & $71(85.5)$ & $37(77.1)$ & \\
\hline Yes & $23(17.6)$ & $12(14.5)$ & II (22.9) & \\
\hline Cardiovascular disease & & & & 0.157 \\
\hline No & $76(58.0)$ & $52(62.7)$ & $24(50.0)$ & \\
\hline Yes & $55(42.0)$ & $31(37.3)$ & $24(50.0)$ & \\
\hline Histology type & & & & 0.88 \\
\hline Transitional cell carcinoma & $110(84.0)$ & $70(84.3)$ & $40(83.3)$ & \\
\hline Non-transitional cell carcinoma & $21(16.0)$ & $13(15.7)$ & $8(16.7)$ & \\
\hline Grade & & & & 0.507 \\
\hline 1 and 2 & $17(13.0)$ & $12(14.5)$ & $5(10.4)$ & \\
\hline 3 & $114(87.0)$ & $71(85.5)$ & $43(89.6)$ & \\
\hline T-stage & & & & 0.001 \\
\hline NMIBC & $54(4 \mid .2)$ & $43(51.8)$ & II (22.9) & \\
\hline MIBC & $77(58.8)$ & $40(48.2)$ & $37(77.1)$ & \\
\hline $\mathbf{N}$-stage & & & & 0.01 \\
\hline Negative & $116(88.5)$ & $78(94.0)$ & $38(79.2)$ & \\
\hline Positive & $15(I I .5)$ & $5(6.0)$ & $10(20.8)$ & \\
\hline M-stage & & & & 0.259 \\
\hline Negative & $125(95.4)$ & 81 (97.6) & $44(91.7)$ & \\
\hline Positive & $6(4.6)$ & $2(2.4)$ & $4(8.3)$ & \\
\hline ASA grade & & & & 0.092 \\
\hline 1 and 2 & $117(89.3)$ & $77(92.8)$ & $40(83.3)$ & \\
\hline 3 and 4 & $14(10.7)$ & $6(7.2)$ & $8(16.7)$ & \\
\hline NLR & & & & $<0.001$ \\
\hline$\leq 3.8$ & $90(68.7)$ & $69(83.1)$ & $21(43.8)$ & \\
\hline$>3.8$ & $4 I(3 I .3)$ & $14(16.9)$ & $27(56.3)$ & \\
\hline PLR & & & & 0.002 \\
\hline$\leq 210.9$ & II $2(85.5)$ & $77(92.8)$ & 35 (72.9) & \\
\hline$>210.9$ & $19(14.5)$ & $6(7.2)$ & $13(27.1)$ & \\
\hline PNI & & & & $<0.001$ \\
\hline$\leq 38.5$ & II4 (87.0) & $80(96.4)$ & $34(70.8)$ & \\
\hline$>38.5$ & $17(13.0)$ & $3(3.6)$ & $14(29.2)$ & \\
\hline
\end{tabular}

Note: $P$-values $<0.05$ are shown in bold.

Abbreviations: ASA, American Society of Anesthesiologists; BMI, body mass index; CAR, C-reactive protein/albumin ratio; MIBC, muscle-invasive bladder cancer; NLR, neutrophil-to-lymphocyte ratio; NMIBC, non-muscle invasive bladder cancer; PLR, platelet-to-lymphocyte ratio; PNI, prognostic nutritional index. 

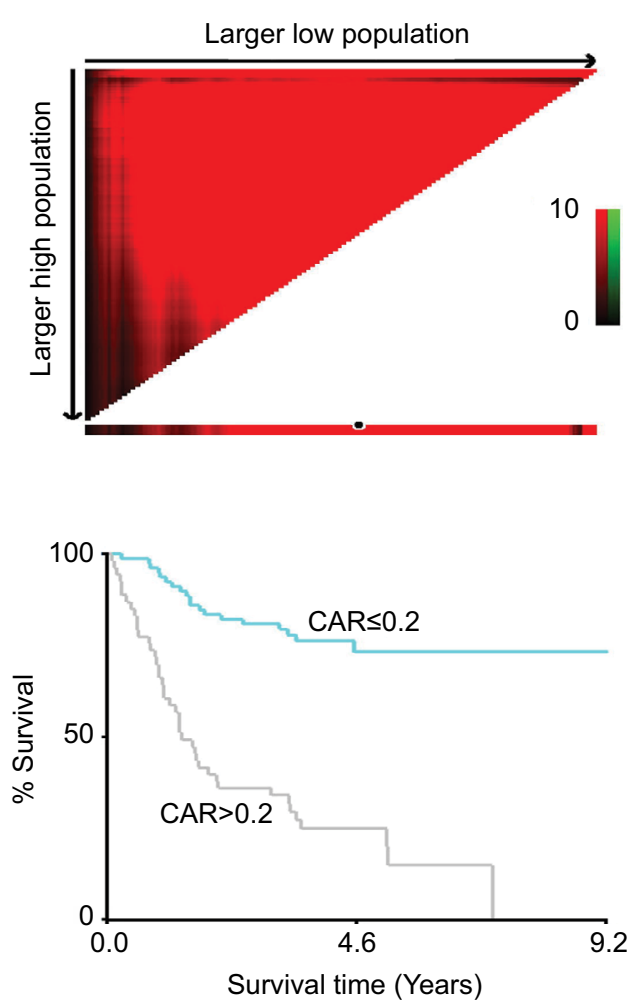

Figure I Cutoff value determination for CAR by X-tile software. Abbreviation: CAR, C-reactive protein/albumin ratio.

\section{Analysis of predictive accuracy through the evaluation of the area under the receiver operating characteristic curve (AUC)}

In order to further validate the predictive accuracy, a receiver operating curve (ROC) analysis for the area under the curve (AUC) was performed to distinguish between these two endpoint events, as shown in Figure 4 and Tables S1 and S2. The ROC curves that show the comparison of OS with the NLR, PLR, PNI, CAR, and CART pretreatment endpoints is presented in Figure 4. The observed AUC for NLR, PLR, PNI, CAR, and CART were 0.575 (95\% CI: 0.486-0.661), 0.548 (95\% CI: 0.459-0.635), 0.578 (95\% CI: 0.489-0.664), 0.709 (95\% CI: $0.624-0.785)$, and 0.838 (95\% CI: 0.764-0.897), respectively. In addition, the comparison of AUCs of the other four inflammation indexes with CART also revealed a statistical significance (all, $P<0.001$ ). Similarly, the analysis of ROC curves for PFS against the NLR, PLR, PNI, CAR, and CART pretreatment endpoints revealed the following AUCs: 0.510 (95\% CI: 0.421-0.598), 0.524 (95\% CI: 0.435-0.612), 0.570 (95\% CI: 0.480-0.656), 0.640 (95\% CI: $0.552-0.722)$, and 0.701 (95\% CI: $0.615-0.778)$, respectively. Importantly, no statistically significant differences in AUCs were observed between CART and CAR. In summary, this data indicated that the predictive power of CAR and CART was higher than NLR, PLR, and PNI for OS in bladder cancer. Moreover, between CAR and CART, the predictive power of CART was clearly higher. Hence, CART can be used as an independent predictor for OS in bladder cancer. This result revealed that the CART index can help to better perform risk stratification for bladder cancer patients, leading to better and guided treatment. However, for PFS, CAR was observed to be an independent predictor in patients with bladder cancer, and its predictive power was better than NLR, PLR, and PNI. Furthermore, compared with CART, CAR had a better predictive value for PFS.

\section{Discussion}

In the present study, using multivariate analyses, it was clearly demonstrated that CAR is an independent predictor of OS $(P<0.001)$ and PFS $(P<0.012)$ in patients with bladder cancer. In addition, AUC analyses further confirmed the prognostic value of CAR over NLR, PLR, and PNI in bladder cancer patients. Furthermore, it was also found that the new prognostic index created based on the combination of CAR and pT staging, called CART, was only independently associated with increased risk of OS in bladder cancer patients. Overall, it appeared that this new prognostic index can be more effective in stratifying high-risk patients, and can guide clinicians on specific postoperative treatments.

Typically, the role of inflammation in cancer has been proposed for a long time. However, more recently, the effect of inflammation on tumors has gradually gained more traction, ${ }^{10,25}$ which is probably due to the reason that the tumor itself is a chronic wasting disease, and inflammation may lead to malnutrition, immune deficiency, the production of growth factors and angiogenesis promotion. There is strong evidence indicating the importance of inflammatory cells in the tumor microenvironment, in which both the tumor microenvironment and systemic inflammation contribute to tumor progression and survival. ${ }^{26,27}$ As an important acute phase protein, CRP has been considered as a stable marker of inflammation, and its hepatic secretion appears to be controlled by IL- $6 .{ }^{28} \mathrm{In}$ one study, it was shown that elevated levels of CRP may help create a favorable microenvironment for tumor cell proliferation and metastasis. ${ }^{29}$ The study conducted by Kramer et al ${ }^{30}$ demonstrated CRP as an independent predictor of bladder cancer clinical outcome. Together, these studies indicate that CRP not only exists as an inflammatory marker, but is also considered as a prognostic indicator of malignancy. In parallel to inflammatory response, nutritional status also exhibits 


\section{A}
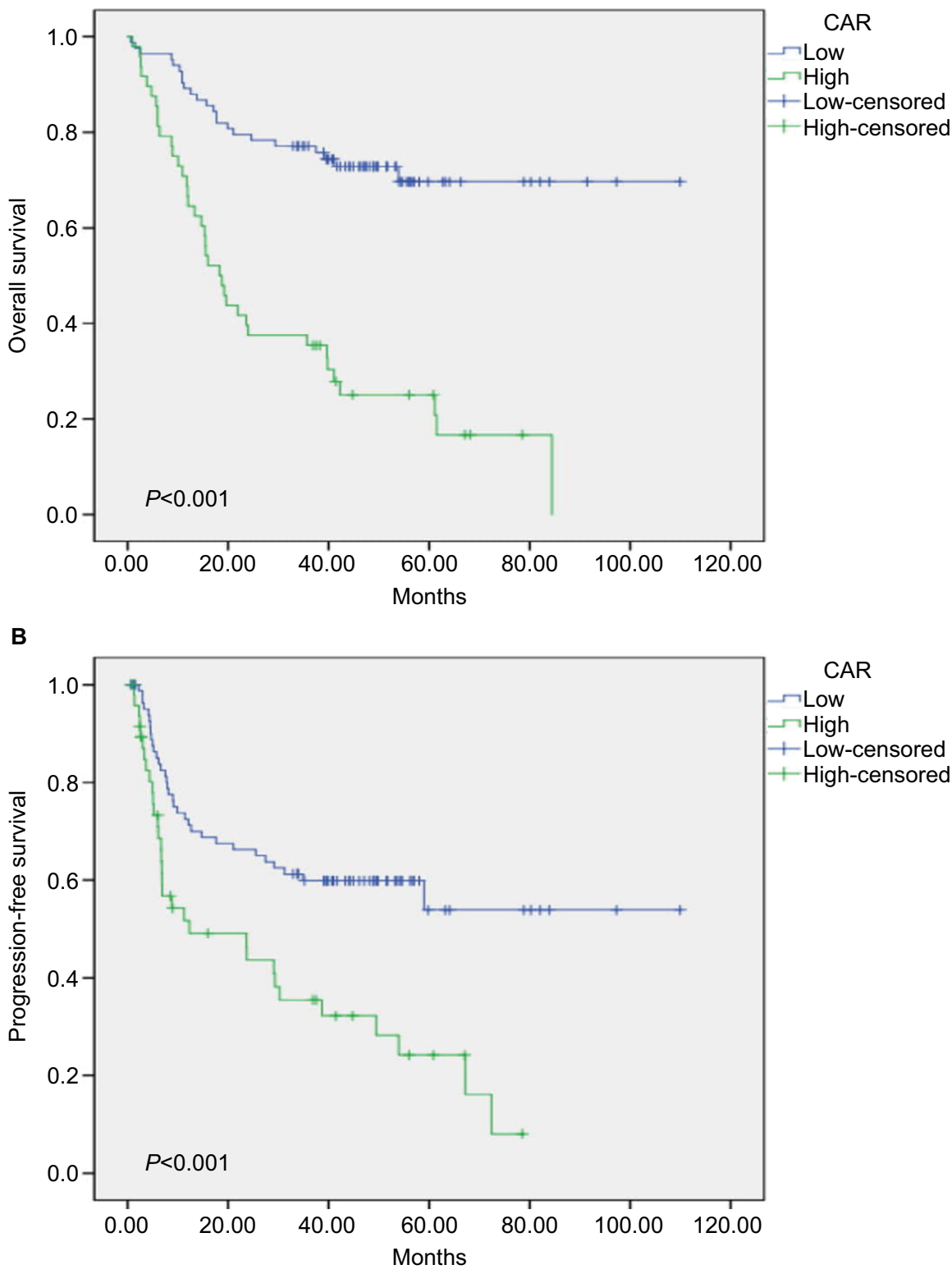

Figure 2 Kaplan-Meier survival curves showing the correlation of the C-reactive protein/albumin ratio with overall survival (A) and progression-free survival (B). Note: The $P$-values were determined using log-rank test.

Abbreviation: CAR, C-reactive protein/albumin ratio.

an important prognostic influence in patients with bladder cancer. Malnutrition and inflammation inhibits the synthesis of serum albumin, which indirectly reflect the nutritional status of the patient, as well as the severity and prognosis of the disease. ${ }^{31}$ Multiple studies have also demonstrated that hypoalbuminemia is an independent risk factor for the prognosis of bladder cancer. ${ }^{32,33}$ Data from the study conducted by Lambert et $\mathrm{al}^{34}$ indicated that low preoperative albumin levels led to increased overall mortality and cancer-specific mortality risk, when compared with normal albumin levels. It has also been demonstrated that higher levels of albumin improve the body's defense mechanism, including cellular immunity, humoral immunity and cell phagocytic function. ${ }^{35}$ Based on the above evidence, it could be realized that serum albumin levels may be a favorable risk factor for tumors, while CRP is an unfavorable risk factor. Based on this information, many studies have combined CRP with serum albumin to create new inflammatory prognostic indicators, such as the Glasgow prognostic score (GPS) and CAR. Both CAR and GPS have been considered as independent risk factors for 
Table 2 Univariate and multivariate analyses of progression-free survival in bladder cancer patients

\begin{tabular}{|c|c|c|c|c|}
\hline Variable & $\begin{array}{l}\text { Univariate analyses } \\
\text { HR }(95 \% \mathrm{Cl})\end{array}$ & $P$-value & $\begin{array}{l}\text { Multivariate analyses } \\
\text { HR }(95 \% \mathrm{Cl})\end{array}$ & $P$-value \\
\hline \multicolumn{5}{|l|}{ Age } \\
\hline$\leq 65$ years & I & 0.155 & & \\
\hline$>65$ years & $\mathrm{I} .428(0.873-2.335)$ & & & \\
\hline \multicolumn{5}{|l|}{ BMI } \\
\hline$<24$ & 1 & 0.904 & & \\
\hline$\geq 24$ & $0.970(0.590-1.594)$ & & & \\
\hline \multicolumn{5}{|l|}{ Gender } \\
\hline Male & I & 0.125 & & \\
\hline Female & $0.518(0.224-1.201)$ & & & \\
\hline \multicolumn{5}{|l|}{ Smoking history } \\
\hline No & 1 & $<0.001$ & I & $<0.001$ \\
\hline Yes & $4.757(2.75 \mathrm{I}-8.225)$ & & $4.128(2.332-7.305)$ & \\
\hline \multicolumn{5}{|l|}{ Hypertension } \\
\hline No & 1 & 0.779 & & \\
\hline Yes & $1.083(0.622-1.883)$ & & & \\
\hline \multicolumn{5}{|l|}{ Diabetes mellitus } \\
\hline No & 1 & 0.167 & & \\
\hline Yes & I.523 (0.839-2.766) & & & \\
\hline \multicolumn{5}{|l|}{ Cardiovascular disease } \\
\hline No & I & 0.337 & & \\
\hline Yes & $0.781(0.472-1.294)$ & & & \\
\hline \multicolumn{5}{|l|}{ Histology type } \\
\hline Transitional cell carcinoma & I & 0.68 & & \\
\hline Non-transitional cell carcinoma & I.I53 (0.587-2.263) & & & \\
\hline \multicolumn{5}{|l|}{ Grade } \\
\hline 1 and 2 & I & 0.169 & & \\
\hline 3 & $1.803(.778-4.178)$ & & & \\
\hline \multicolumn{5}{|l|}{ T-stage } \\
\hline NMIBC & I & $<0.001$ & I & 0.003 \\
\hline MIBC & $3.797(2.14 I-6.736)$ & & $2.445(1.345-4.443)$ & \\
\hline \multicolumn{5}{|l|}{ N-stage } \\
\hline Negative & 1 & 0.028 & - & - \\
\hline Positive & $2.139(1.084-4.223)$ & & & \\
\hline \multicolumn{5}{|l|}{ M-stage } \\
\hline Negative & I & 0.198 & & \\
\hline Positive & 1.951 (0.706-5.389) & & & \\
\hline \multicolumn{5}{|l|}{ ASA grade } \\
\hline 1 and 2 & 1 & 0.033 & 1 & 0.043 \\
\hline 3 and 4 & $2.167(1.065-4.409)$ & & $2.128(1.025-4.416)$ & \\
\hline \multicolumn{5}{|l|}{ NLR } \\
\hline$\leq 3.8$ & I & 0.155 & & \\
\hline$>3.8$ & $1.453(0.868-2.432)$ & & & \\
\hline \multicolumn{5}{|l|}{ PLR } \\
\hline$\leq 210.9$ & 1 & 0.206 & & \\
\hline$>210.9$ & $1.525(0.793-2.934)$ & & & \\
\hline \multicolumn{5}{|l|}{ PNI } \\
\hline$\leq 38.5$ & 1 & 0.006 & - & - \\
\hline$>38.5$ & $0.426(0.23 I-0.786)$ & & & \\
\hline \multicolumn{5}{|l|}{ CAR } \\
\hline$\leq 0.2$ & I & $<0.001$ & 1 & 0.012 \\
\hline$>0.2$ & $2.401(1.473-3.916)$ & & $1.893(1.150-3.114)$ & \\
\hline
\end{tabular}

Note: $P$-values $<0.05$ are shown in bold.

Abbreviations: ASA, American Society of Anesthesiologists; BMI, body mass index; CAR, C-reactive protein/albumin ratio; MIBC, muscle-invasive bladder cancer; NLR, neutrophil-to-lymphocyte ratio; NMIBC, non-muscle invasive bladder cancer; PLR, platelet-to-lymphocyte ratio; PNI, prognostic nutritional index. 
Table 3 Univariate and multivariate analyses of overall survival in bladder cancer patients

\begin{tabular}{|c|c|c|c|c|}
\hline Variable & $\begin{array}{l}\text { Univariate analyses } \\
\text { HR }(95 \% \mathrm{Cl})\end{array}$ & $P$-value & $\begin{array}{l}\text { Multivariate analyses } \\
\text { HR }(95 \% \mathrm{Cl})\end{array}$ & $P$-value \\
\hline \multicolumn{5}{|l|}{ Age } \\
\hline$\leq 65$ years & I & 0.01 & - & - \\
\hline$>65$ years & $1.958(1.175-3.354)$ & & & \\
\hline \multicolumn{5}{|l|}{ BMI } \\
\hline$<24$ & 1 & 0.277 & & \\
\hline$\geq 24$ & $0.747(0.442-1.264)$ & & & \\
\hline \multicolumn{5}{|l|}{ Gender } \\
\hline Male & 1 & 0.504 & & \\
\hline Female & $0.764(0.347-1.68 I)$ & & & \\
\hline \multicolumn{5}{|l|}{ Smoking history } \\
\hline No & I & $<0.001$ & I & $<0.001$ \\
\hline Yes & $5.046(2.800-9.093)$ & & $4.169(2.218-7.835)$ & \\
\hline \multicolumn{5}{|l|}{ Hypertension } \\
\hline No & I & 0.323 & & \\
\hline Yes & $1.365(0.736-2.531)$ & & & \\
\hline \multicolumn{5}{|l|}{ Diabetes mellitus } \\
\hline No & 1 & 0.702 & & \\
\hline Yes & $1.118(0.632-1.978)$ & & & \\
\hline \multicolumn{5}{|l|}{ Cardiovascular disease } \\
\hline No & 1 & 0.542 & & \\
\hline Yes & $0.85 I(0.507-I .429)$ & & & \\
\hline \multicolumn{5}{|l|}{ Histology type } \\
\hline Transitional cell carcinoma & & 0.44 & & \\
\hline Non-transitional cell carcinoma & $1.295(0.673-2.492)$ & & & \\
\hline \multicolumn{5}{|l|}{ Grade } \\
\hline 1 and 2 & 1 & 0.295 & & \\
\hline 3 & $1.569(0.675-3.647)$ & & & \\
\hline \multicolumn{5}{|l|}{ T-stage } \\
\hline NMIBC & 1 & $<0.001$ & 1 & 0.001 \\
\hline MIBC & $6.084(2.983-12.408)$ & & $3.36 \mathrm{I}(1.60 \mathrm{I}-7.055)$ & \\
\hline \multicolumn{5}{|l|}{ N-stage } \\
\hline Negative & I & 0.018 & - & - \\
\hline Positive & $2.221(1.147-4.301)$ & & & \\
\hline \multicolumn{5}{|l|}{ M-stage } \\
\hline Negative & I & 0.018 & 1 & 0.006 \\
\hline Positive & $3.035(1.208-7.625)$ & & $4.006(1.494-10.742)$ & \\
\hline \multicolumn{5}{|l|}{ ASA grade } \\
\hline 1 and 2 & I & 0.013 & - & - \\
\hline 3 and 4 & $2.385(1.204-4.724)$ & & & \\
\hline \multicolumn{5}{|l|}{ NLR } \\
\hline$\leq 3.8$ & 1 & $<0.001$ & - & - \\
\hline$>3.8$ & $2.754(1.655-4.584)$ & & & \\
\hline \multicolumn{5}{|l|}{ PLR } \\
\hline$\leq 210.9$ & 1 & 0.01 & - & - \\
\hline$>210.9$ & $2.248(1.212-4.167)$ & & & \\
\hline \multicolumn{5}{|l|}{ PNI } \\
\hline$\leq 38.5$ & I & 0.002 & - & - \\
\hline$>38.5$ & $0.380(0.208-0.692)$ & & & \\
\hline \multicolumn{5}{|l|}{ CAR } \\
\hline$\leq 0.2$ & I & $<0.001$ & I & $<0.001$ \\
\hline$>0.2$ & $4.214(2.500-7.102)$ & & $3.063(1.788-5.249)$ & \\
\hline
\end{tabular}

Note: $P$-values $<0.05$ are shown in bold.

Abbreviations: ASA, American Society of Anesthesiologists; BMI, body mass index; CAR, C-reactive protein/albumin ratio; MIBC, muscle-invasive bladder cancer; NLR, neutrophil-to-lymphocyte ratio; NMIBC, non-muscle invasive bladder cancer; PLR, platelet-to-lymphocyte ratio; PNI, prognostic nutritional index. 


\section{A}

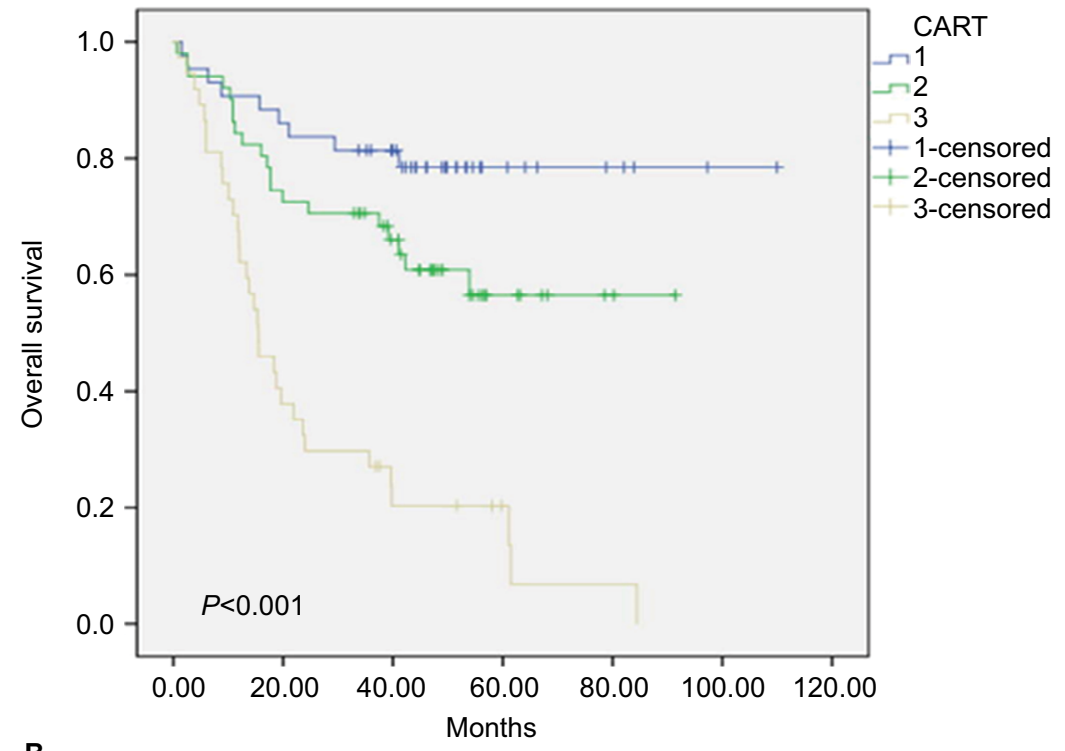

B

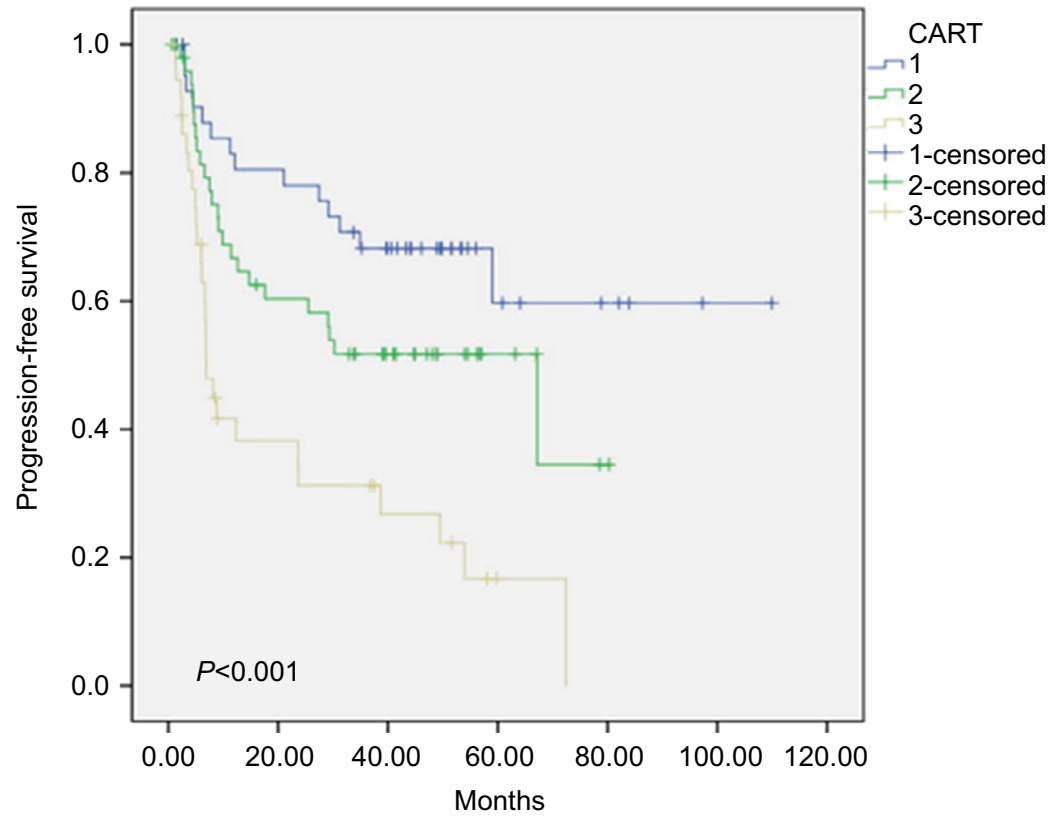

Figure 3 Kaplan-Meier survival curves showing the correlation of CART with overall survival (A) and progression-free survival (B).

Note: The $P$-values were determined using the log-rank test.

Abbreviations: CART, CAR and PT staging index; CAR, C-reactive protein/albumin ratio.

the prognosis of various tumors. ${ }^{36,37}$ However, since the relationship between CAR and bladder cancer remains unclear, the investigators attempted to combine CRP with albumin to form a new prognostic factor in bladder cancer after RC.

In the present study, in addition to CAR, other prognostic indicators of inflammation, such as PNI, PLR, and NLR, were also analyzed, which have been widely studied in the prognosis of bladder cancer. The present analysis revealed that low PNI, and high PLR and NLR are independent prognostic risk factors in bladder cancer after surgery. ${ }^{16-18}$ However, CAR was uniquely observed to be a superior prognostic factor in multivariate analyses, when compared to PNI, PLR, and NLR for OS and PFS in bladder cancer. Moreover, CAR depicted a higher predictive prognostic value. Next, the present study also revealed that CAR and pT staging are independent risk factors for the prognosis of bladder cancer. Therefore, the investigators attempted to combine CAR and pT staging with intent to establish a 
Table 4 Univariate and multivariable analysis of factors associated with progression-free survival in bladder cancer patients, who underwent radical cystectomy, including CART

\begin{tabular}{|c|c|c|c|c|}
\hline Variable & $\begin{array}{l}\text { Univariate analyses } \\
\text { HR }(95 \% \mathrm{Cl})\end{array}$ & $P$-value & $\begin{array}{l}\text { Multivariate analyses } \\
\text { HR }(95 \% \mathrm{Cl})\end{array}$ & $P$-value \\
\hline \multicolumn{5}{|l|}{ Age } \\
\hline$\leq 65$ years & I & 0.155 & & \\
\hline$>65$ years & $1.428(0.873-2.335)$ & & & \\
\hline \multicolumn{5}{|l|}{ BMI } \\
\hline$<24$ & $\mathrm{I}$ & 0.904 & & \\
\hline$\geq 24$ & $0.970(0.590-1.594)$ & & & \\
\hline \multicolumn{5}{|l|}{ Gender } \\
\hline Male & I & 0.125 & & \\
\hline Female & $0.518(0.224-1.201)$ & & & \\
\hline \multicolumn{5}{|l|}{ Smoking history } \\
\hline No & $\mathrm{I}$ & $<0.001$ & I & $<0.001$ \\
\hline Yes & $4.757(2.75 \mathrm{I}-8.225)$ & & $4.128(2.332-7.305)$ & \\
\hline \multicolumn{5}{|l|}{ Hypertension } \\
\hline No & $\mathrm{I}$ & 0.779 & & \\
\hline Yes & $1.083(0.622-1.883)$ & & & \\
\hline \multicolumn{5}{|l|}{ Diabetes mellitus } \\
\hline No & I & 0.167 & & \\
\hline Yes & $1.523(0.839-2.766)$ & & & \\
\hline \multicolumn{5}{|l|}{ Cardiovascular disease } \\
\hline No & $\mathrm{I}$ & 0.337 & & \\
\hline Yes & $0.78 \mid(0.472-1.294)$ & & & \\
\hline \multicolumn{5}{|l|}{ Histology type } \\
\hline Transitional cell carcinoma & I & 0.68 & & \\
\hline Non-transitional cell carcinoma & I.I53 (0.587-2.263) & & & \\
\hline \multicolumn{5}{|l|}{ Grade } \\
\hline 1 and 2 & 1 & 0.169 & & \\
\hline 3 & $\mathrm{I} .803(0.778-4.178)$ & & & \\
\hline \multicolumn{5}{|l|}{ T-stage } \\
\hline NMIBC & I & $<0.001$ & 1 & 0.003 \\
\hline MIBC & $3.797(2.14 I-6.736)$ & & $2.445(1.345-4.443)$ & \\
\hline \multicolumn{5}{|l|}{ N-stage } \\
\hline Negative & I & 0.028 & - & - \\
\hline Positive & $2.139(1.084-4.223)$ & & & \\
\hline \multicolumn{5}{|l|}{ M-stage } \\
\hline Negative & 1 & 0.198 & & \\
\hline Positive & 1.951 (0.706-5.389) & & & \\
\hline \multicolumn{5}{|l|}{ ASA grade } \\
\hline 1 and 2 & I & 0.033 & 1 & 0.043 \\
\hline 3 and 4 & $2.167(1.065-4.409)$ & & $2.128(1.025-4.416)$ & \\
\hline \multicolumn{5}{|c|}{$2.108(1.000-4.407)$} \\
\hline$\leq 3.8$ & I & 0.155 & & \\
\hline$>3.8$ & I.453 (0.868-2.432) & & & \\
\hline \multicolumn{5}{|l|}{ PLR } \\
\hline$\leq 210.9$ & I & 0.206 & & \\
\hline$>210.9$ & $1.525(0.793-2.934)$ & & & \\
\hline \multicolumn{5}{|l|}{ PNI } \\
\hline$\leq 38.5$ & I & 0.006 & - & - \\
\hline$>38.5$ & $0.426(0.231-0.786)$ & & & \\
\hline \multicolumn{5}{|l|}{ CAR } \\
\hline$\leq 0.2$ & I & $<0.001$ & 1 & 0.012 \\
\hline$>0.2$ & $2.401(1.473-3.916)$ & & $1.893(1.150-3.114)$ & \\
\hline \multicolumn{5}{|l|}{ CART } \\
\hline I & 1 & & - & - \\
\hline 2 & $0.244(0.127-0.470)$ & $<0.001$ & & \\
\hline 3 & $0.434(0.250-0.755)$ & 0.003 & & \\
\hline
\end{tabular}

Note: $P$-values $<0.05$ are shown in bold.

Abbreviations: ASA, American Society of Anesthesiologists; BMI, body mass index; CAR, C-reactive protein/albumin ratio; CART, CAR and PT staging index; MIBC, muscle-invasive bladder cancer; NLR, neutrophil-to-lymphocyte ratio; NMIBC, non-muscle invasive bladder cancer; PLR, platelet-to-lymphocyte ratio; PNI, prognostic nutritional index. 
Table 5 Univariate and multivariable analysis of factors associated with overall survival in bladder cancer patients, who underwent radical cystectomy, including CART

\begin{tabular}{|c|c|c|c|c|}
\hline Variable & $\begin{array}{l}\text { Univariate analyses } \\
\text { HR }(95 \% \mathrm{Cl})\end{array}$ & $P$-value & $\begin{array}{l}\text { Multivariate analyses } \\
\text { HR }(95 \% \mathrm{Cl})\end{array}$ & $P$-value \\
\hline \multicolumn{5}{|l|}{ Age } \\
\hline$\leq 65$ years & I & 0.01 & - & - \\
\hline$>65$ years & $1.958(1.175-3.354)$ & & & \\
\hline \multicolumn{5}{|l|}{ BMI } \\
\hline$<24$ & I & 0.277 & & \\
\hline$\geq 24$ & $0.747(0.442-1.264)$ & & & \\
\hline \multicolumn{5}{|l|}{ Gender } \\
\hline Male & I & 0.504 & & \\
\hline Female & $0.764(0.347-1.68 I)$ & & & \\
\hline \multicolumn{5}{|l|}{ Smoking history } \\
\hline No & I & $<0.001$ & I & $<0.001$ \\
\hline Yes & $5.046(2.800-9.093)$ & & $4.235(2.254-7.955)$ & \\
\hline \multicolumn{5}{|l|}{ Hypertension } \\
\hline No & 1 & 0.323 & & \\
\hline Yes & $1.365(0.736-2.531)$ & & & \\
\hline \multicolumn{5}{|l|}{ Diabetes mellitus } \\
\hline No & I & 0.702 & & \\
\hline Yes & I.II8 (0.632-1.978) & & & \\
\hline \multicolumn{5}{|l|}{ Cardiovascular disease } \\
\hline No & I & 0.542 & & \\
\hline Yes & 0.85 I (0.507-I.429) & & & \\
\hline \multicolumn{5}{|l|}{ Histology type } \\
\hline Transitional cell carcinoma & I & 0.44 & & \\
\hline Non-transitional cell carcinoma & $1.295(0.673-2.492)$ & & & \\
\hline \multicolumn{5}{|l|}{ Grade } \\
\hline 1 and 2 & I & 0.295 & & \\
\hline 3 & $1.569(0.675-3.647)$ & & & \\
\hline \multicolumn{5}{|l|}{ T-stage } \\
\hline NMIBC & I & $<0.001$ & 1 & 0.007 \\
\hline MIBC & $6.084(2.983-12.408)$ & & $2.99 \mid(I .35 I-6.624)$ & \\
\hline \multicolumn{5}{|l|}{ N-stage } \\
\hline Negative & I & 0.018 & - & - \\
\hline Positive & $2.221(I .147-4.30 I)$ & & & \\
\hline \multicolumn{5}{|l|}{ M-stage } \\
\hline Negative & 1 & 0.018 & 1 & 0.001 \\
\hline Positive & $3.035(1.208-7.625)$ & & $5.022(I .863-3.54 I)$ & \\
\hline \multicolumn{5}{|l|}{ ASA grade } \\
\hline 1 and 2 & 1 & 0.013 & 1 & 0.022 \\
\hline 3 and 4 & $2.385(1.204-4.724)$ & & $2.555(1.145-5.704)$ & \\
\hline \multicolumn{5}{|c|}{ 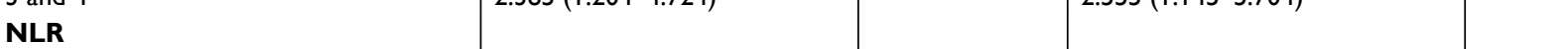 } \\
\hline$\leq 3.8$ & I & $<0.001$ & - & - \\
\hline$>3.8$ & $2.754(1.655-4.584)$ & & & \\
\hline \multicolumn{5}{|l|}{ PLR } \\
\hline$\leq 210.9$ & 1 & 0.01 & 1 & 0.029 \\
\hline$>210.9$ & $2.248(1.212-4.167)$ & & $2.045(1.077-3.883)$ & \\
\hline \multicolumn{5}{|l|}{ PNI } \\
\hline$\leq 38.5$ & I & 0.002 & - & - \\
\hline$>38.5$ & $0.380(0.208-0.692)$ & & & \\
\hline \multicolumn{5}{|l|}{ CAR } \\
\hline$\leq 0.2$ & I & $<0.001$ & - & - \\
\hline$>0.2$ & $4.214(2.500-7.102)$ & & & \\
\hline \multicolumn{5}{|l|}{ CART } \\
\hline I & 1 & & I & \\
\hline 2 & $0.141(0.067-0.297)$ & $<0.001$ & $0.264(0.106-0.660)$ & 0.004 \\
\hline 3 & $0.297(0.169-0.523)$ & $<0.001$ & $0.37 \mathrm{I}(0.208-0.66 \mathrm{I})$ & 0.001 \\
\hline
\end{tabular}

Note: $P$-values $<0.05$ are shown in bold.

Abbreviations: ASA, American Society of Anesthesiologists; BMI, body mass index; CAR, C-reactive protein/albumin ratio; CART, CAR and PT staging index; MIBC, muscle-invasive bladder cancer; NLR, neutrophil-to-lymphocyte ratio; NMIBC, non-muscle invasive bladder cancer; PLR, platelet-to-lymphocyte ratio; PNI, prognostic nutritional index. 


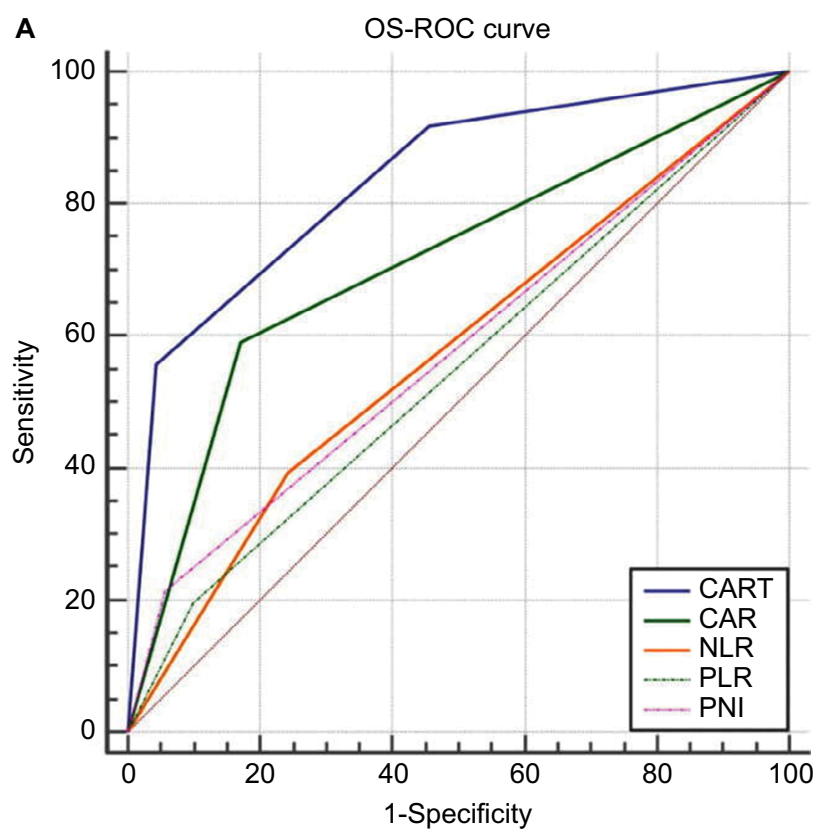

B

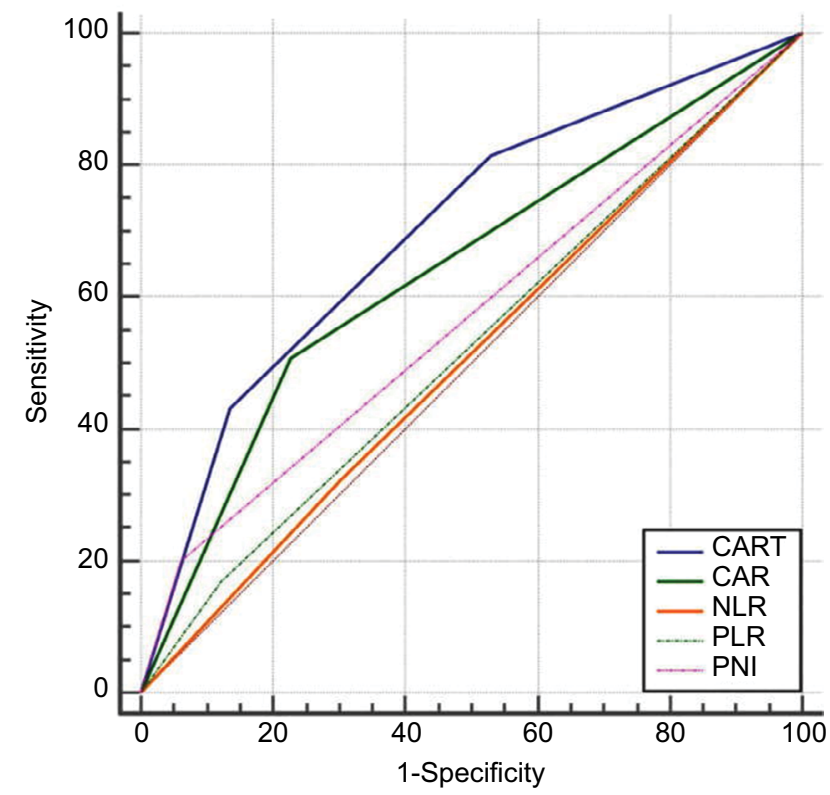

Figure 4 Receiver operating characteristic curve analysis for CART, CAR, NLR, PLR, and PNI against OS (A) and PFS (B).

Abbreviations: OS, overall survival; PFS, progression-free survival; CART, CAR and $P T$ staging index; CAR, C-reactive protein/albumin ratio; NLR, neutrophil-tolymphocyte ratio; PLR, platelet-to-lymphocyte ratio; PNI, prognostic nutritional index.

new index with more accuracy in predicting the prognosis of patients with bladder cancer after RC. The present multivariate analysis confirmed CART as an independent predictor for OS in bladder cancer, and the ROC curve analysis further validated its predictive prognostic power for OS, but showed no advantage for PFS. Since evidence of CAR-based clinical effects constantly emerge, it would be obvious to screen patients with different risks based on preoperative clinical pathology and CAR, which may help guide the use of early cystectomy. In the same direction, the use of the CART score can further improve patient stratification, and subsequently result in benefiting patients with higher risk of clinically localized diseases, by focusing on loco-regional and systemic adjuvant therapy in patients with the highest risk of regional and systemic failure.

Finally, the present study has some limitations. First, the present study is a retrospective observational study conducted in a single institution, which makes it prone to selection bias. Second, as the investigators were not able to regularly measure the blood cell count after RC, it could not be determined whether changes in the biomarkers based on blood cell counts have any predictive value. Third, the number of patients in the present study was relatively small. Fourth, it remains unclear whether the clinical applications of CAR and CART can be generalized for all bladder cancer patients, except for RC patients. Thus, the ability and accuracy of CAR and CART in the prognosis of patients with bladder cancer require additional independent prospective and multicenter studies, in order to validate these present findings.

\section{Conclusion}

CAR can act as new prognostic indicator for patients with bladder cancer after RC. In addition, combining the CAR score with pT staging, as the CART score, appears to be a more effective prognostic indicator for poor OS, but not PFS. These indicators also have the ability to stratify patients based on risk, and select appropriate treatment strategies for bladder cancer patients.

\section{Acknowledgments}

This work was supported by the National Natural Science Foundation of the People's Republic of China (grant number: 81472389)

\section{Disclosure}

The authors report no conflicts of interest in this work.

\section{References}

1. Siegel RL, Miller KD, Jemal A. Cancer statistics, 2018. CA Cancer J Clin. 2018;68(1):7-30.

2. Spiess PE, Agarwal N, Bangs R, et al. Bladder cancer, Version 5. 2017, NCCN Clinical Practice Guidelines in Oncology. J Natl Compr Canc Netw. 2017;15(10):1240-1267.

3. Miller KD, Siegel RL, Lin CC, et al. Cancer treatment and survivorship statistics, 2016. CA Cancer J Clin. 2016;66(4):271-289. 
4. Fahmy O, Khairul-Asri MG, Schubert T, et al. A systematic review and meta-analysis on the oncological long-term outcomes after trimodality therapy and radical cystectomy with or without neoadjuvant chemotherapy for muscle-invasive bladder cancer. Urol Oncol. 2018;36(2):43-53.

5. Kulkarni GS, Hakenberg OW, Gschwend JE, et al. An updated critical analysis of the treatment strategy for newly diagnosed high-grade T1 (previously T1G3) bladder cancer. Eur Urol. 2010;57(1):60-70.

6. Tu Y, Johnstone CN, Stewart AG. Annexin A1 influences in breast cancer: Controversies on contributions to tumour, host and immunoediting processes. Pharmacol Res. 2017;119:278-288.

7. Takagi K, Umeda Y, Yoshida R, et al. Preoperative controlling nutritional status score predicts mortality after hepatectomy for hepatocellular carcinoma. Dig Surg. 2018;35(3).

8. Zhang Q, Zhu B, Li Y. Resolution of cancer-promoting inflammation: a new approach for anticancer therapy. Front Immunol. 2017;8:71.

9. Bindea G, Mlecnik B, Fridman WH, Pagès F, Galon J. Natural immunity to cancer in humans. Curr Opin Immunol. 2010;22(2):215-222.

10. Coussens LM, Werb Z. Inflammation and cancer. Nature. 2002;420(6917):860-867.

11. Coffelt SB, de Visser KE. Cancer: inflammation lights the way to metastasis. Nature. 2014;507(7490):48-49.

12. Mantovani A, Allavena P, Sica A, Balkwill F. Cancer-related inflammation. Nature. 2008;454(7203):436-444.

13. Xavier P, Belo L, Beires J, et al. Serum levels of VEGF and TNF-alpha and their association with C-reactive protein in patients with endometriosis. Arch Gynecol Obstet. 2006;273(4):227-231.

14. Santana Porbén S. State of malnutrition in Cuban hospitals; a needed update. Nutr Hosp. 2015;31(5):1900-1909.

15. van Cutsem E, Arends J. The causes and consequences of cancerassociated malnutrition. Eur J Oncol Nurs. 2005;9(Suppl 2):S51-S63.

16. Lee SM, Russell A, Hellawell G. Predictive value of pretreatment inflammation-based prognostic scores (neutrophil-to-lymphocyte ratio, platelet-to-lymphocyte ratio, and lymphocyte-to-monocyte ratio) for invasive bladder carcinoma. Korean J Urol. 2015;56(11):749-755.

17. Kawahara T, Furuya K, Nakamura M, et al. Neutrophil-to-lymphocyte ratio is a prognostic marker in bladder cancer patients after radical cystectomy. BMC Cancer. 2016;16:185.

18. Peng D, Gong YQ, Hao H, et al. Preoperative prognostic nutritional index is a significant predictor of survival with bladder cancer after radical cystectomy: a retrospective study. BMC Cancer. 2017;17(1):391.

19. Kinoshita A, Onoda H, Imai N, et al. The C-reactive protein/albumin ratio, a novel inflammation-based prognostic score, predicts outcomes in patients with hepatocellular carcinoma. Ann Surg Oncol. 2015;22(3):803-810.

20. Hang J, Xue P, Yang H, et al. Pretreatment C-reactive protein to albumin ratio for predicting overall survival in advanced pancreatic cancer patients. Sci Rep. 2017;7(1):2993.

21. Yamauchi Y, Safi S, Muley T, et al. C-reactive protein-albumin ratio is an independent prognostic predictor of tumor recurrence in stage IIIA-N2 lung adenocarcinoma patients. Lung Cancer. 2017;114:62-67.

22. Wei XL, Wang FH, Zhang DS, et al. A novel inflammation-based prognostic score in esophageal squamous cell carcinoma: the C-reactive protein/albumin ratio. BMC Cancer. 2015;15:350.
23. Zhang W, Liu K, Ye B, Liang W, Ren Y. Pretreatment C-reactive protein/ albumin ratio is associated with poor survival in patients with stage IB-IIA cervical cancer. Cancer Med. 2018;7(1):105-113.

24. Camp RL, Dolled-Filhart M, Rimm DL. X-tile: a new bio-informatics tool for biomarker assessment and outcome-based cut-point optimization. Clin Cancer Res. 2004;10(21):7252-7259.

25. Hanahan D, Weinberg RA. Hallmarks of cancer: the next generation. Cell. 2011;144(5):646-674.

26. Roxburgh CS, Mcmillan DC. Cancer and systemic inflammation: treat the tumour and treat the host. Br J Cancer. 2014;110(6):1409-1412.

27. Bunt SK, Yang L, Sinha P, Clements VK, Leips J, Ostrand-Rosenberg $\mathrm{S}$. Reduced inflammation in the tumor microenvironment delays the accumulation of myeloid-derived suppressor cells and limits tumor progression. Cancer Res. 2007;67(20):10019-10026.

28. Shrotriya S, Walsh D, Bennani-Baiti N, Thomas S, Lorton C. C-reactive protein is an important biomarker for prognosis tumor recurrence and treatment response in adult solid tumors: a systematic review. PLoS One. 2015;10(12):e0143080.

29. Asegaonkar SB, Asegaonkar BN, Takalkar UV, Advani S, Thorat AP. $\mathrm{C}$-reactive protein and breast cancer: new insights from old molecule. Int J Breast Cancer. 2015;2015:145647-6.

30. Kramer MW, Heinisch A, Wegener G, et al. C-reactive protein prior to radical cystectomy: preoperative determination of CRP. Urologe A. 2014;53(2):222-227.

31. Ballmer PE, Ochsenbein AF, Schütz-Hofmann S. Transcapillary escape rate of albumin positively correlates with plasma albumin concentration in acute but not in chronic inflammatory disease. Metabolism. 1994:43(6):697-705.

32. Djaladat H, Bruins HM, Miranda G, Cai J, Skinner EC, Daneshmand $\mathrm{S}$. The association of preoperative serum albumin level and American Society of Anesthesiologists (ASA) score on early complications and survival of patients undergoing radical cystectomy for urothelial bladder cancer. BJU Int. 2014;113(6):887-893.

33. Zhang Y, Li F, Yang F, et al. Prognostic value of preoperative serum albumin in patients with non-muscle-invasive bladder cancer undergoing transurethral resection of bladder tumor. Nan Fang Yi Ke Da Xue Xue Bao. 2018;38(2):192-197.

34. Lambert JW, Ingham M, Gibbs BB, Given RW, Lance RS, Riggs $\mathrm{SB}$. Using preoperative albumin levels as a surrogate marker for outcomes after radical cystectomy for bladder cancer. Urology. 2013;81(3):587-592.

35. Sonnenschein C, Soto AM, Michaelson CL. Human serum albumin shares the properties of estrocolyone-I, the inhibitor of the proliferation of estrogen-target cells. J Steroid Biochem Mol Biol. 1996;59(2):147-154.

36. Wu J, Tan W, Chen L, Huang Z, Mai S. Clinicopathologic and prognostic significance of C-reactive protein/albumin ratio in patients with solid tumors: an updated systemic review and meta-analysis. Oncotarget. 2018;9(17):13934-13947.

37. Li MX, Bi XY, Li ZY, et al. Prognostic role of Glasgow prognostic score in patients with hepatocellular carcinoma: a systematic review and meta-analysis. Medicine. 2015;94(49):e2133. 


\section{Supplementary materials}

Table SI Receiver operating characteristic curve pairwise comparison analysis for CART, CAR, NLR, PLR, and PNI against OS

\begin{tabular}{|l|l|l|l|}
\hline Variable & AUC & SE & $95 \% \mathbf{C l}$ \\
\hline CART & 0.701 & 0.0428 & $0.615-0.778$ \\
\hline CAR & 0.64 & 0.0406 & $0.552-0.722$ \\
\hline NLR & 0.51 & 0.0408 & $0.42 I-0.598$ \\
\hline PLR & 0.524 & 0.031 & $0.435-0.612$ \\
\hline PNI & 0.57 & 0.0291 & $0.480-0.656$ \\
\hline Comparison & SE & P-value & \\
\hline CART CAR & 0.0401 & 0.1283 & \\
\hline CART NLR & 0.0531 & 0.0003 & \\
\hline CART PLR & 0.0477 & 0.0002 & \\
\hline CART PNI & 0.0452 & 0.0037 & \\
\hline CAR NLR & 0.0438 & 0.003 & \\
\hline CAR PLR & 0.0442 & 0.0086 & \\
\hline CAR PNI & 0.0416 & 0.0897 & \\
\hline NLR PLR & 0.0379 & 0.7122 & \\
\hline NLR PNI & 0.037 & 0.1067 & \\
\hline PLR PNI & 0.0343 & 0.1822 & \\
\hline
\end{tabular}

Abbreviations: CART, CAR and PT staging index; CAR, C-reactive protein/albumin ratio; NLR, neutrophil-to-lymphocyte ratio; PLR, platelet-to-lymphocyte ratio; PNI, prognostic nutritional index; OS, overall survival.

Table S2 Receiver operating characteristic curve pairwise comparison analysis for CART, CAR, NLR, PLR, and PNI against PFS

\begin{tabular}{|l|l|l|l|}
\hline Variable & AUC & SE & $\mathbf{9 5 \%} \mathbf{C l}$ \\
\hline CART & 0.838 & 0.0322 & $0.764-0.897$ \\
\hline CAR & 0.709 & 0.039 & $0.624-0.785$ \\
\hline NLR & 0.575 & 0.0408 & $0.486-0.661$ \\
\hline PLR & 0.548 & 0.0314 & $0.459-0.635$ \\
\hline PNI & 0.578 & 0.0299 & $0.489-0.664$ \\
\hline Comparison & SE & P-value & \\
\hline CART $\sim$ CAR & 0.0381 & 0.0007 & \\
\hline CART NLR & 0.0482 & $<0.0001$ & \\
\hline CART $\sim$ PLR & 0.0416 & $<0.0001$ & \\
\hline CART $\sim$ PNI & 0.039 & $<0.0001$ & \\
\hline CAR NLR & 0.0443 & 0.0025 & \\
\hline CAR PLR & 0.0442 & 0.0003 & \\
\hline CAR PNI & 0.0415 & 0.0015 & \\
\hline NLR PLR & 0.0385 & 0.4837 & \\
\hline NLR PNI & 0.0375 & 0.9427 & \\
\hline PLR PNI & 0.0352 & 0.4007 & \\
\hline
\end{tabular}

Abbreviations: CART, CAR and PT staging index; CAR, C-reactive protein/albumin ratio; NLR, neutrophil-to-lymphocyte ratio; PLR, platelet-to-lymphocyte ratio; PNI, prognostic nutritional index; PFS, progression-free survival. 

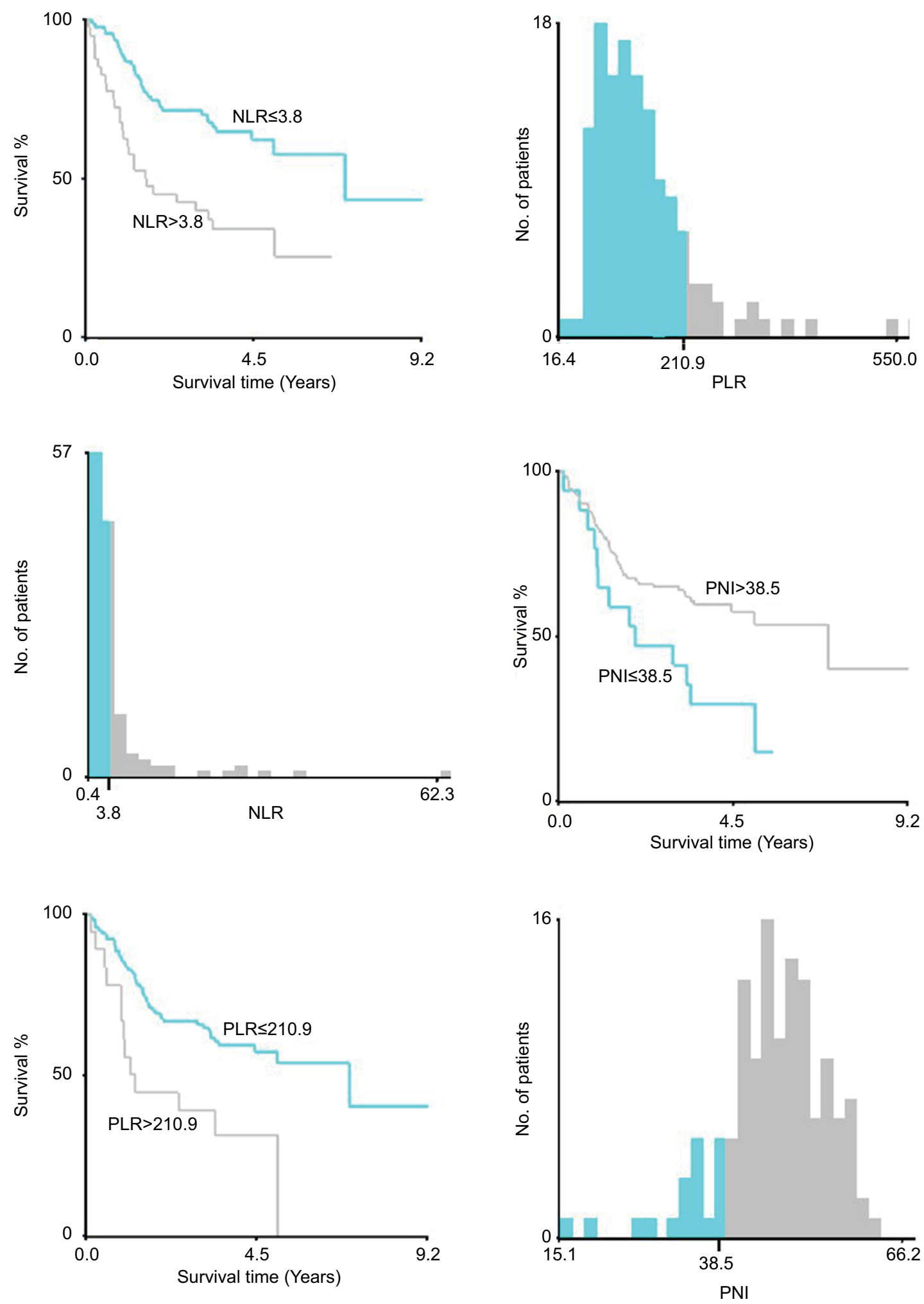

Figure SI Cutoff value determination for NLR, PLR, and PNI by X-tile software.

Abbreviations: NLR, neutrophil-to-lymphocyte ratio; PLR, platelet-to-lymphocyte ratio; PNI, prognostic nutritional index. 


\section{Publish your work in this journal}

Cancer Management and Research is an international, peer-reviewed open access journal focusing on cancer research and the optimal use of preventative and integrated treatment interventions to achieve improved outcomes, enhanced survival and quality of life for the cancer patient. The manuscript management system is completely online and includes a very quick and fair peer-review system, which is all easy to use. Visit http://www.dovepress.com/testimonials.php to read real quotes from published authors.

Submit your manuscript here: https://www.dovepress.com/cancer-management-and-research-journal 